\title{
Analysis of Tuberculosis Cases Notification and Treatment Outcomes Among Refugee Camps In Kenya: Four Year Retrospective Study, 2014-2017
}

\section{Tsegay Legesse}

Intergovernmental Authority on Development (IGAD)

\section{Stephen Mulesh}

National TB program, Ministry of Health, Kenya

Dorothy Anjuri

Thai Red Cross Society

\section{Miriam Ngure}

American Red Cross

\section{Salad Chiari}

Kenya Red Cross Society

\section{Fredrick Chepkwong}

Kenya Red Cross Society

Job Okemwa

National TB Program, Ministry of Heath, Kenya

Adbirushid Diney

National TB program, Ministry of Heath, Kenya

Abdillah Frah

National TB Program, Ministry of Health,Kenya , ,

\section{Fathia Alwan}

Intergovernmental Authority on Development, IGAD

Desta Kassa ( $\sim$ dkassa2003@gmail.com )

Intergovernmental Authority on Developments (IGAD)

\section{Research article}

Keywords: Tuberculosis, refugees, case notification, Treatment outcome

Posted Date: December 3rd, 2020

DOI: https://doi.org/10.21203/rs.3.rs-116530/v1 
License: (c) (i) This work is licensed under a Creative Commons Attribution 4.0 International License. Read Full License 


\section{Abstract}

Background: Tuberculosis (TB) is more severe in refugee populations. Analyzing the key indicators of TB program performance is important to improve the effectiveness of TB control in the refugee camps. This study aimed to analyze trends in TB case notification, treatment outcomes and factors associated with unsuccessful TB treatment in Dadaab and Kakuma refugee camps in Kenya.

Methods: In this descriptive retrospective study, demographic and clinical data all TB cases registered in the refugee camps from January 2014 to December 2017 were extracted. Multiple logistic regression analysis was used to estimate odds ratios and $95 \%$ confidence intervals for variables associated with unsuccessful TB treatment.

Results. A total of 2055 TB cases of whom $56.8 \%$ men and $57.7 \%$ age $15-44$ years were registered. Number of notified cases decreased from 532 in 2014 to 473 in 2016 (11.1\% decrease) then increased to 554 in 2017(16.9\% increase in one year). From 2014 to 2017 there was consistent increase in percentage of EPTB ( $16.2 \%$ to $21.1 \%$ ), and in contribution of children ( $<15$ years) to total TB cases $(20.3 \%$ to $25.8 \%)$ and to EPTB (36.1\% to $44.4 \%)$. Proportion of bacteriologically confirmed new and relapse pulmonary cases increased from $49.5 \%$ to $60.9 \%$. Treatment success rate remained higher at $92.6 \%$ to $94.4 \%$. On average $41.7 \%$ were cured, $2.3 \%$ lost to follow-up (LTFU) (increasing from $1.3 \%$ to $3.2 \%$ ), $2.2 \%$ died (decreasing from $2.4 \%$ to $1.6 \%$ ), $1.6 \%$ not evaluated (decreasing from $3.2 \%$ to $1.3 \%$ ), and $0.5 \%$ treatment failed. Unsuccessful treatment outcome was significantly associated with pretreatment weight $<40 \mathrm{Kg}$, being male, smear positive PTB, HIV infection, and age $>15$ years (increased with age).

Conclusions: Number of notified TB cases has decreased from 2014 to 2016, but increased in 2017. There was continuous increase in percentage of EPTB and childhood TB. Proportion of bacteriologically confirmed new and relapse pulmonary cases has increased overtime. Treatment success remained higher above global target $(90 \%)$ which should be maintained. Special socioeconomic support and follow-up is required for TB patients who are at higher risk of unsuccessful treatment.

\section{Background}

Tuberculosis (TB) is an ancient infectious disease caused primarily by Mycobacterium tuberculosis [1]. Although the burden of TB has been declined in the past 20 years (58 million lives have been saved and TB incidence was declined $1.6 \%$ per year), TB remains to be the leading cause of death from single infectious agent above HIV/AIDS. In 2018, there were an estimated 10 million incident TB cases and 1.6 million TB deaths among HIV negative in the globe [2]. Kenya, is among the 30 high burden countries for TB, TB/HIV and MDR-TB. By 2018, the estimated TB incident, HIV negative TB mortality, and notified TB cases in Kenya was 150000, 96478 and 38 000, respectively [2]. Overall, based on the global success stories, but also taking into account the existing challenges to control TB (missed TB cases, TB/HIV, MDR-TB, TB in high risk groups, budget gaps), the global plan is to end the TB epidemic by 2035 (less than 10 cases per 100000 population) [3]. 
TB, however, is a major health problem in key populations (refugees, immigrants, prisoners, homeless, internally displaced persons (IDPs). The reasons for which are poor shelter/housing, inadequate living conditions, limited health service access/use, poor nutritional status, coexistent illness like HIV, overcrowding, and inadequate TB care and prevention, $[4,5,6]$. Thus, TB infection and disease progression [4-6], acquiring or developing multi-drug resistant (MDR) TB [7] and unsuccessful TB treatment outcome [8] is higher among refugees.

Reports showed armed conflicts and population displacements are associated with up to 20 -fold increase in the risk of TB [6]. In 2018, there were 70.8 million refugees, asylum seekers and persons displaced by wars and conflicts Worldwide [9]. Usually, majority $(>85 \%)$ of refugees originate from and remain within countries with high burdens of TB [10]. A recent systemic review and meta-analysis showed that TB prevalence in refugees and asylum seekers varied more according to countries of origin than the host country [11], whereas others reported association between continuous immigration (increase in migrant population) and increase in prevalence of PTB and EPTB [12], in TB case notification [13] and in case detection rate [14].

To address the TB burden in the key populations, and also to achieve the global targets and end TB by 2030, special focus has been given to these key populations in the WHO Stop TB (2006-2015) [15] and End TB (2016-2020) [3) strategic documents. The proposed targets for high-risk groups are to screen $90 \%$ of the population for TB and to obtain at least $90 \%$ treatment success by 2020 [3].

Kenya (population size 51 million) is among the 30 high burden countries for TB, TB/HIV and MDR-TB in the globe [2]. In 2017, Kenya hosted 434009 refugees in three refugee camps, Dadaab (54.8\%), Kakuma, (36.9\%) and Nairobi (8.4\%) [16]. Daddab and Kakuma, which are included in this study, are among the largest refugee camps in the world. They started hosting refugees since 1991 and 1992, respectively. The number of refugees hosted in both Daddab and Kakuma in 2014, 2015, 2016, and 2017 (during this study period) were $378505,381508,312713$ and 395870 , respectively. Majority $(>56 \%)$ of the refugees registered from 2014 to 2017 are in Dadaab.

Nonetheless, majority (> 90\%) of the refugees hosted in Daddab and Kakuma from 2014 to 2017 originate from countries whose TB is predominate which are (in descending order) Somalia, South Sudan, DR Congo and Ethiopia (5.7\%), and the remaining are from Uganda, Eritrea, Sudan, Burundi and Rwanda [14].

In summary, considering the factors including high TB burden in the host country (Kenya) [2] and in the countries of origin of the refugees in Kenya [14], the large refugee population residing in the host country [14], and the higher vulnerability of the refugee population to TB infection and disease [4-6], to MDR-TB [7] and to unsuccessful TB treatment outcome [8], TB can be a major health challenge in the refugee populations in Kenya. In north-east Kenya in 1994, the incidence of new infectious TB patients in camps was four times the rate in the local population [10]. 
Hence, in order to prevent and control TB in the refugee camps effectively, the performance of TB programs need to be monitored and evaluated regularly. Among the main indicators for TB program performance are TB case notification and treatment outcome $[17,18]$. In countries that have highperformance of surveillance and monitoring and evaluation systems, notifications of TB cases provide good proxy information on TB incidence (TB burden), whereas TB treatment outcomes provide information on the effectiveness of TB treatment program [18]. In this study, therefore, we aimed to investigate the trends of TB case notification, TB treatment outcome, and factors associated with unsuccessful TB treatment outcomes in refugee camps in Kenya in the past four years (2014-2017).

\section{Methods}

Study settings and populations

In Kenya, the structure of health service delivery is hierarchical with six tiers, namely community level followed by dispensaries, health centres, primary referral, secondary referral, and tertiary facilities. TB control and prevention program in Kenya, which is integrated to the general health care delivery system, is implemented by the National TB, Leprosy and Lung Disease Programme (NTLD-P), in the Department of Disease Prevention and Control, under the Ministry of Health (MOH). In Kenya, there are 3320 treatment facilities, 1920 diagnostic, and 295 TB control Zones located in 47 counties [19]. Similarly, health facilities in the refugee camps in Kenya (Dadaab, Kakuma and other urban areas) deliver general health care services including TB prevention and control to the refugee population. The TB programs in the refugee camps are led by the NTLD-P according to the national guideline for integrated Tuberculosis, Leprosy and Lung disease in Kenya [19].

Dadaab and Kakuma, which are among the world's largest refugee camps, hosted above $90 \%$ of the refugees in Kenya. Dadaab refugee camp located in Garissa County has three camps namely Dagahaley, IFO and Hagadera. Dagahaley and IFO are located in Lagdera sub-county and Hagadera is located in the neighbouring Fafi sub-county. Kakuma refugee camp, located in Turkana County, has two areas of operation which are Kakuma Camp and Kalobeyei Integrated Settlement both located in Turkana West sub-county [16].

According to the inclusion critrea, heatlh facilites which have both TB diagnosis and treatment services starting from January 2017 will be included to address the objectives of this study. Thus, three health facilites loacted in three camps in Dadaab (Dagahaley, IFO1 and Hagadera) and two health facilities located in Kakuma refugee camp (IRC Kakuma General Hospital and Kalobeyei Hospital) are included (Supplement 1). The study population were all TB cases of all forms registered from January 2014 to December 2017 in three health facilities in Dadaab (Dagahaley, IFO1 and Hagadera) and in two health facilities in Kakuma (IRC Kakuma General Hospital and Kalobeyei)

Study design, data collection and management 
In this four year (2014-2017) refugee health facility based descriptive retrospective study, basic demographic and clinical data of each TB cases registered in Dadaab and Kakuma refugee camps were extracted from TB patient register. Data collection was done by trained health officers and nurses using pretested data collection forms from January to April 2019. The data collection forms were pre-tested during the training of the data collectors, supervisors and coordinators. During the training, a previously filled in and archived TB register in the refugee health facilities was used as a sample to show each trainee on how to extract data from the TB register and on how to fill the data collection form. Finally, the data collection forms were revised as per the suggestion and comments received from pre-test exercise.

To ensure data quality, data collectors, study coordinators and supervisors were trained; supervision was done on daily basis by field supervisors and on weekly basis by study coordinators during data collection; and then $10 \%$ of the data collected were randomly selected by the study coordinators, re-collected by the field supervisors, and were checked page by page.

Data entry and statistical analysis

Data were coded and double entered into Epi-info version 7 by two trained data clerks and then crosschecked for consistency. During the preliminary analysis we looked for errors and corrected them by rechecking the data collection Forms. Binary logistic regression analysis was done to identify independent variables associated with unsuccessful treatment outcome. Finally, multivariate logistic regression analysis was used to measure the independent effects of each predictor variable on unsuccessful treatment outcomes. Variables with a P-value of $<0.05$ in the bivariate analysis were included in the multivariate model. The independent variables used were age, sex, baseline weight, type of TB, category of TB, and HIV and ART status. Statistical significance level was considered at a P-value $<0.05$. Odds ratios with $95 \%$ confidence interval were used to assess the strength of association between variables.

\section{Definitions Of Variables And Terms}

As shown in Supplement 2, TB case definition and TB treatment outcomes were defined according to the standard definitions in the National guidelines for integrated TB, Leprosy and lung disease in Kenya [19] and the WHO guideline [17].

\section{Results}

\subsection{Characteristics of the study participants.}

The clinical and demographic characteristics of all TB cases notified is shown in Table 1. From 2014 to 2017, a total of 2055 TB cases of all forms, mean age 27.0 years, 167 (56.8\%) males and $857(41.7 \%)$ females were registered. Children under 15 years and adults $15-44$ years represented $23.8 \%$ and $57.8 \%$ of the total TB cases, respectively. Of the total TB cases, 1685 (82.0\%) were PTB, 364 (17.7\%) EPTB, and no record found for $6(0.3)$. 
By treatment history, 2034 (99.0\%) of the total cases were new and relapse patients of whom 1767 $(86.0 \%)$ were PTB patients. Among the new and relapse pulmonary patients, 988 (55.9\%) were bacteriologically confirmed and 779 (44.1\%) were clinically diagnosed.

By refugee camps, 1094 (53.2\%) of the notified cases were from Dadaab and 961 (46.8\%) cases were from Kakuma camp. The number of notified cases in Dadaab continuously decreased from 2014 (332 cases) to 2017 (242 cases), while in Kakuma refugee it increased from 2014 (200 cases) to 2017 (232 cases). The number of TB cases registered in the three health facilities in Dadaab refugee camp, and in two health facilities in Kakuma refugee camp is shown in Supplement 1. 
Table 1

Characteristic of the notified TB cases of all forms in Dadaab and Kakuma refugee camps, Kenya, 2014$2017(\mathrm{~N}=2055)$

\begin{tabular}{|c|c|c|c|c|c|}
\hline Characteristic & $\begin{array}{l}2014, \\
\text { N (\%) }\end{array}$ & $\begin{array}{l}2015, \\
N(\%)\end{array}$ & $\begin{array}{l}2016, \\
\text { N (\%) }\end{array}$ & $\begin{array}{l}2017, \\
\text { N (\%) }\end{array}$ & $\begin{array}{l}\text { Total } \\
(2014- \\
2017)\end{array}$ \\
\hline $\begin{array}{l}\text { Total TB cases of all Forms } \\
\text { notified }\end{array}$ & 532 & 496 & 473 & 554 & 2055 \\
\hline Mean age, years & 28.5 & 26.9 & 26.8 & 28.4 & 27.7 \\
\hline Age groups, years & $108(20.3)$ & $133(26.8)$ & $104(22.0)$ & $143(25.8)$ & $488(23.7)$ \\
\hline$<15$ & $201(37.8)$ & $161(32.4)$ & $178(37.6)$ & $177(31.9)$ & $717(34.9)$ \\
\hline $15-29$ & $123(23.1)$ & $104(21.0)$ & $122(25.8)$ & $119(21.5)$ & $468(22.8)$ \\
\hline $30-44$ & $51(9.6)$ & $58(11.7)$ & $40(8.5)$ & $53(9.6)$ & $202(9.8)$ \\
\hline $45-59$ & $42(7.9)$ & $35(7.1)$ & $27(5.7)$ & $61(11.0)$ & $165(8.0)$ \\
\hline$>=60$ & $7(1.3)$ & $5(1.0)$ & $2(0.4)$ & $1(0.2)$ & $15(0.7)$ \\
\hline \multicolumn{6}{|l|}{ Not recorded } \\
\hline Gender, & $305(57.3)$ & $292(58.9)$ & $267(56.4)$ & $303(54.7)$ & $1167(56.8)$ \\
\hline Male & $214(40.2)$ & $191(38.5)$ & $204(43.1)$ & $248(44.8)$ & $857(41.7)$ \\
\hline Female & $13(2.4)$ & $13(0.6)$ & $2(0.5)$ & $3(0.5)$ & $31(1.5)$ \\
\hline \multicolumn{6}{|l|}{ Not recorded } \\
\hline Male to Female (M:F) ratio & 1.3 & 1.5 & 1.3 & 1.2 & 1.4 \\
\hline Type of TB & $446(83.8)$ & $425(85.7)$ & $380(80.3)$ & $434(78.3)$ & $1685(82.0)$ \\
\hline PTB & $86(16.2)$ & $68(13.7)$ & 93 (19.7) & $117(21.1)$ & $364(17.7)$ \\
\hline EPTB & 0 & $3(0.6)$ & 0 & $3(0.6)$ & $6(0.3)$ \\
\hline \multicolumn{6}{|l|}{ Not recorded } \\
\hline Type of TB by diagnostic & $222(41.7)$ & $225(45.4)$ & $283(59.8)$ & $263(47.5)$ & $993(48.3)$ \\
\hline & $224(42.1)$ & $200(40.3)$ & $97(20.5)$ & $171(30.9)$ & $692(33.6)$ \\
\hline & $86(16.2)$ & $68(13.7)$ & 93 (19.7) & $117(21.1)$ & $364(17.7)$ \\
\hline EPTB & 0 & $3(0.6)$ & 0 & $3(0.5)$ & $6(0.3)$ \\
\hline Not recorded & & & & & \\
\hline
\end{tabular}




\begin{tabular}{|c|c|c|c|c|c|}
\hline Characteristic & $\begin{array}{l}2014, \\
N(\%)\end{array}$ & $\begin{array}{l}2015, \\
\text { N (\%) }\end{array}$ & $\begin{array}{l}2016, \\
N(\%)\end{array}$ & $\begin{array}{l}2017, \\
\mathrm{~N}(\%)\end{array}$ & $\begin{array}{l}\text { Total } \\
\text { (2014- } \\
2017)\end{array}$ \\
\hline Type of TB Patients & $528(99.2)$ & $490(98.8)$ & $465(98.3)$ & $551(99.4)$ & $2034(99.0)$ \\
\hline New and relapse $e^{\star \star}$ & 0 & 0 & 0 & 0 & 0 \\
\hline Treatment after Failure & 0 & 0 & 0 & 0 & 0 \\
\hline Lost to Follow up to Treatment & 0 & 0 & $6(1.3)$ & 0 & $6(0.3)$ \\
\hline Others & $4(0.8)$ & $6(1.2)$ & $2(0.4)$ & $3(0.6)$ & $15(0.7)$ \\
\hline \multicolumn{6}{|l|}{ Missed $\star \star \star$} \\
\hline $\begin{array}{l}\text { New and relapse -PTB } \\
\text { patients: }\end{array}$ & $\begin{array}{l}442 \\
(83.7 \%)\end{array}$ & $\begin{array}{l}420 \\
(85.7 \%)\end{array}$ & $\begin{array}{l}373 \\
(80.2 \%)\end{array}$ & $\begin{array}{l}432 \\
(78.4 \%)\end{array}$ & $\begin{array}{l}1767 \\
(86.9 \%)\end{array}$ \\
\hline Bacteriologically confirmed & $219(49.5)$ & $224(53.3)$ & $282(75.6)$ & $263(60.9)$ & 988 (55.9) \\
\hline Clinically diagnosed & $223(50.5)$ & $296(46.7)$ & $91(25.4)$ & $169(39.1)$ & $779(44.1)$ \\
\hline HIV status & $62(11.8)$ & $50(10.4)$ & $54(11.5)$ & $40(7.4)$ & $206(10.0)$ \\
\hline Positive & $464(88.2)$ & $433(89.6)$ & $414(88.5)$ & $498(92.6)$ & $1809(88.0)$ \\
\hline Negative & $6(1.1)$ & $13(2.6)$ & $5(1.1)$ & $16(2.9)$ & $40(1.9)$ \\
\hline \multicolumn{6}{|l|}{ Not documented } \\
\hline ART initiation & $42(67.7)$ & $49(98.0)$ & $54(100)$ & $39(97.5)$ & $184(89.3)$ \\
\hline Yes & $20(32.3)$ & $1(2.0)$ & 0 & $1(2.5)$ & $22(10.7)$ \\
\hline \multicolumn{6}{|l|}{ No } \\
\hline TB cases by refugee camps & $332(62.4)$ & $262(52.8)$ & $242(51.1)$ & $258(46.6)$ & $1094(53.2)$ \\
\hline Dadaab & $200(37.6)$ & $234(47.2)$ & $231(48.9)$ & $296(53.4)$ & $961(46.8)$ \\
\hline Kakuma & & & & & \\
\hline
\end{tabular}

PTB + = Smear-positive pulmonary TB

\section{*Clinically diagnosed PTB}

includes smear-negative pulmonary TB and pulmonary smear unknown/not done

\section{** New and relapse}

includes cases for which the treatment history is unknown (not recorded) and transfer in; and it excludes cases that have been re-registered as treatment after failure, as treatment after lost to follow up or as other previously treated with unknown or undocumented treatment outcome 
*** Missed: patients with no information about previous treatment history of TB in the unit TB register or in the data collection format

\subsection{Overall trends in TB case notification (2014-2017)}

Trends in TB case notification by diagnostic category and treatment history

The number of notified TB cases decreased from 532 in 2014 to 473 cases in 2016 (11.1\% decrease in 3 years) and increased to 554 in 2017 (17.1\% increase in one years). Among the total cases, percentage of PTB decreased from 83.8-78.3\%, and that of EPTB increased from 16.2-21.1\% (30.2\% increase in four years) (Table 1).

Among the total PTB cases, the percentage of smear-positive pulmonary TB (PTB+) increased from $41.7 \%$ in 2014 to $59.8 \%$ in 2016 then decreased to $47.5 \%$ in 2017 , whereas those clinically diagnosed (smear-negative pulmonary TB plus pulmonary smear unknown/not done) decreased from $42.1 \%$ in 2014 to $30.9 \%$ in 2017 (a decrease in 26.6\%) (Table 1 \& Fig. 1). Among the pulmonary new and relapse patients, those bacteriologically confirmed increased from $49.5 \%$ in 2014 to $60.9 \%$ in 2017 , and clinically diagnosed patients decreased from $50.5-30.1 \%$. (Table 1 ).

By treatment history, new and relapse patients remained stable and highest (98.3\%-99.4\%), whereas on average treatment after failure, lost to follow up to treatment, "others", and missed (no record) patients constituted $0 \%, 0 \%, 0.3 \%$, and $0.7 \%$, respectively.

Figure 1. Trends in number of TB cases notified (bar) by diagnostic category (line) in Dadaab and Kakuma refugee camps, Kenya, 2014-2017.

Trends in TB case notification by gender

There was variation in notified TB cases by gender. The average number of notified cases for men was 292 (standard deviation, $S D=17.5)$ and for women was $214(S D=24.4)(P=0.002)$. Over the study period, the proportion of notified cases for men was higher (>55\%) with the male-to-female (M:F) ratio of notification consistently >1.2:1. However, the number of notified cases for both men and women decreased from 2014 to 2016 and then increased by 2017, but predominated by men; and the M:F ratio was increased from 1.4 in 2014 to 1.5 in 2015, then declined to 1.3 in 2016, and 1.2 in 2017 (Table 1).

Trends in TB case notification by age categories

There was a variation in number of notified cases by age groups (Fig. 2). Younger age groups (1529 years) were the largest contributors (32.0\%-37.8\%) to the total TB cases notified across the study period (2014 to 2017). The second largest contributors were children < 15 years $(20.7 \%-27.0 \%)$ and those $30-44$ years old $(21.0 \%-25.9 \%)$, where their contribution was comparable over the years.

The share of children to the total TB cases increased from $20.6 \%$ in 2014 to $25.9 \%$ in 2017 . Likewise, the contribution of children ( $<15$ years) to the total EPTB was highest across the years and continuously 
increased from 2014 (36.1\%) to 2015 (51.5\%), 2016 (40.9\%) to 2017 (44.4\%).

Figure 2. Trends in notified TB case of all forms stratified by age categories in Dadaab and Kakuma refugee camps, Kenya, 2014-2017

Trends in TB case notification segregated by gender and age groups

TB affects people of both sexes in all age groups but the highest burden was in men (Fig. 3). The percentage of notified TB cases was higher for men $(>50 \%)$ than for women in all age groups $(<15,15-$ $29,30-44,45-59$ and $>60$ years) and across the years (2014-2017), except for age 30-44 years in 2014 and 2016, and age $<15$ and 45-59 years in 2017. Generally, the proportion of case notification for women decreases as age increase across the years.

Figure 3. Trends in TB cases notified segregated by age and gender in Dadaab and Kakuma refugee camps, Kenya, 2014-2017

\subsection{Trends in HIV testing and antiretroviral treatment coverage}

Among the 2055 notified TB cases, HIV testing was done for 2015 (98.1\%) patients, of whom 206 (10.0\%) were HIV positive. During the study period, $97.1 \%-99.4 \%$ of the TB cases were tested for HIV; HIV positive rate has decreased continuously from $11.8 \%$ in 2014 to $7.4 \%$ in 2017 ; and antiretroviral treatment (ART) increased from $67.7 \%$ in 2014 to $97.5 \%$ in 2017 (Table 1).

\subsection{Trend in TB Treatment outcomes, 2014-2017}

TB Treatment outcome was evaluated for TB patients of all forms registered from 2014 to 2017(Table 2). From 2014 to 2017, treatment success rate remained stable and higher at $92.6 \%-94.9 \%$ (on average $41.7 \%$ were cured and $51.6 \%$ treatment completed). On average $6.7 \%$ had unfavorable treatment outcome including 2.3\% LTFU (increasing 1.3-3.2\%), 2.2\% died (decreasing from 2.4-1.6\%), 1.6\% not evaluated (decreasing $3.2-1.3 \%$ ), and $0.3 \%$ treatment failed (increasing $0.2-0.9 \%$ ). The percentage of cured patients increased from $34.8 \%$ in 2014 to $52.0 \%$ in 2016 , then decreased sharply to $39.7 \%$ in 2017 . 
Table 2

Trends of TB treatment outcome for all TB cases registered in Dadaab and Kakuma refugee camps, Kenya, 2014-2017 ( $\mathrm{N}=2055)$

\begin{tabular}{|c|c|c|c|c|c|}
\hline \multirow[t]{2}{*}{ Treatment outcomes } & \multicolumn{5}{|l|}{ Years } \\
\hline & $\begin{array}{l}2014 \\
(N=532)\end{array}$ & $2015(N=496)$ & $\begin{array}{l}2016 \\
(N=473)\end{array}$ & $\begin{array}{l}2017 \\
(N=554)\end{array}$ & $\begin{array}{l}\text { Total } \\
(\mathrm{N}=2055)\end{array}$ \\
\hline Cured & $185(34.8)$ & $206(41.5)$ & $246(52.0)$ & $220(39.7)$ & $857(41.7)$ \\
\hline Treatment completed & $309(58.1)$ & $265(53.4)$ & $192(40.6)$ & $295(53.2)$ & $1061(51.6)$ \\
\hline Treatment Failed & $1(0.2)$ & $4(0.8)$ & $1(0.2)$ & $5(0.9)$ & $11(0.5)$ \\
\hline LTFU & $7(1.3)$ & $9(1.8)$ & $14(3.0)$ & $18(3.2)$ & $48(2.3)$ \\
\hline Died & $13(2.4)$ & $10(2.0)$ & $13(2.8)$ & $9(1.6)$ & $45(2.2)$ \\
\hline Not evaluated & $17(3.2)$ & $2(0.4)$ & $7(1.5)$ & $7(1.3)$ & $33(1.6)$ \\
\hline Success rate & 492 (92.9) & $471(94.9)$ & $438(92.6)$ & $515(92.9)$ & $1916(93.3)$ \\
\hline
\end{tabular}

Data are presented as numbers (\%)

Trend of treatment success rate by gender, age, and type of TB

There was a variation in treatment success rate by gender, age category and type of TB (Fig. 4A-C). From 2014 to 2017: there was higher treatment success rate for EPTB (95.7\%-98.9\%) than for PTB (91.0\%-94.3\%) cases (Fig. 4A); for females (93.5\%-96.3\%) than for males (90.6\%-93.8\%) (Fig. 4B); and for children $<15$ years $(96.5 \%-100 \%)$ than for adults $15+$ years old $(91.0 \%-93.7 \%)$, where the least success rate was for those age 45.59 years (Fig. 4C).

Figure 4. Trends in TB treatment outcomes of the TB cases registered in Dadaab and Kakuma refugee camps, Kenya, 2014-2017: by Type of TB (A), by gender (B), and by age category (C)

\subsection{Multivariate analysis to identify factors independently associated with unsuccessful outcome}

Based on a multivariable analysis, factors associated with unsuccessful treatment outcome (LTFU, failed, and died) among TB patients of all forms were age 15-29 years (aOR 4.5, 95\% Cl:1.3-15.5, $P=0.01$ ), age 30-44 years (aOR 5.7, 95\% Cl:1.6-19.6, $P=0.006$ ), age $45-59$ years (aOR 6.0, 95\% Cl:1.6-22.3, $P=$ 0.007 ), age above 60 years (aOR 6.1,95\% Cl:1.6-23.2, $P=0.007)$, pretreatment weight $<40 \mathrm{Kg}(\mathrm{aOR}=1.9$, $95 \% \mathrm{Cl}: 1.1-3.1, P=0.01)$, being PTB+ $(\mathrm{aOR}=2.2,95 \% \mathrm{Cl}: 1.3-3.8, P=0.003)$, and HIV infection $(\mathrm{aOR}=$ $3.9,95 \% \mathrm{Cl}: 2.4-6.5, P<0.001)($ Table 3$)$ 
Table 3

Factors associated with unsuccessful TB treatment outcomes among TB cases of all Forms in Dadaab and Kakuma refugee camps, Kenya, 2014- 2017

\begin{tabular}{|c|c|c|c|c|c|c|c|}
\hline \multirow[t]{2}{*}{ Characteristics } & \multirow[t]{2}{*}{$\begin{array}{l}\text { Successful } \\
\text { outcomes }\end{array}$} & \multirow[t]{2}{*}{$\begin{array}{l}\text { Unsuccessful } \\
\text { outcomes }\end{array}$} & \multirow{2}{*}{$\begin{array}{l}\mathrm{x}^{2} \\
\mathrm{p} \text { - } \\
\text { value }\end{array}$} & \multicolumn{2}{|l|}{$\begin{array}{l}\text { Bivariate } \\
\text { analysis }\end{array}$} & \multicolumn{2}{|c|}{$\begin{array}{l}\text { Multivariable } \\
\text { analysis }\end{array}$} \\
\hline & & & & $\begin{array}{l}\text { OR } \\
(95 \% \mathrm{Cl})\end{array}$ & $\begin{array}{l}P \\
\text { value }\end{array}$ & $\begin{array}{l}\text { Adjusted } \\
\text { OR } \\
(95 \% \mathrm{Cl})\end{array}$ & $\begin{array}{l}P \\
\text { value }\end{array}$ \\
\hline \multirow{2}{*}{$\begin{array}{l}\text { Gender } \\
\text { Female } \\
\text { Male }\end{array}$} & $811(96.4)$ & $30(3.6)$ & 8.1; & 1 & \multirow[t]{2}{*}{0.005} & \multirow{2}{*}{$\begin{array}{l}2(1.3- \\
3.3)\end{array}$} & \multirow[t]{2}{*}{0.004} \\
\hline & 1076 (92.4) & $74(6.4)$ & 0.005 & $\begin{array}{l}1.9 \\
(1.2- \\
2.8)\end{array}$ & & & \\
\hline Age group & 479 (98.8) & $6(1.2)$ & \multirow{7}{*}{$\begin{array}{l}22.1 \\
0.001\end{array}$} & 1 & \multirow{3}{*}{$\begin{array}{l}<.001 \\
< \\
0.001\end{array}$} & \multirow{2}{*}{$\begin{array}{l}4.5(1.3- \\
15.5)\end{array}$} & 0.015 \\
\hline \multirow{2}{*}{$\begin{array}{l}<15 \\
15-29\end{array}$} & $662(94.3)$ & $40(5.7)$ & & \multirow{2}{*}{$\begin{array}{l}1.8(2.0- \\
11.5)\end{array}$} & & & 0.006 \\
\hline & $426(92.6)$ & $34(7.4)$ & & & & $\begin{array}{l}5.7(1.6- \\
19.6)\end{array}$ & 0.007 \\
\hline \multirow{4}{*}{$\begin{array}{l}30-44 \\
45-59 \\
>=60\end{array}$} & $182(92.9)$ & $14(7.1)$ & & \multirow{2}{*}{$\begin{array}{l}6.4 \\
(2.6- \\
15.3)\end{array}$} & $<001$ & \multirow{2}{*}{$\begin{array}{l}6.0(1.6- \\
22.3)\end{array}$} & \multirow[t]{4}{*}{0.007} \\
\hline & 155 (94.5) & $9(5.5)$ & & & & & \\
\hline & & & & $\begin{array}{l}(2.3- \\
16.2)\end{array}$ & 0.001 & $23.2)$ & \\
\hline & & & & $\begin{array}{l}4.6 \\
(1.6- \\
13.2)\end{array}$ & & & \\
\hline \multirow{2}{*}{$\begin{array}{l}\text { Pre-treatment } \\
\text { weight, kg } \\
>40 \\
<40\end{array}$} & 1090 (92.9) & $67(5.8)$ & 3.0 & 1 & \multirow[t]{2}{*}{0.08} & \multirow{2}{*}{$\begin{array}{l}1.9(1.1- \\
3.1)\end{array}$} & \multirow[t]{2}{*}{0.01} \\
\hline & 304 (91.6) & $28(8.4)$ & 0.08 & $\begin{array}{l}1.5 \\
(0.9- \\
2.4)\end{array}$ & & & \\
\hline \multirow{3}{*}{$\begin{array}{l}\text { Type of TB } \\
\text { P/Neg } \\
\text { PTB+ }\end{array}$} & $460(96.2)$ & $18(3.8)$ & 34.6 & 1 & 0.003 & \multirow{5}{*}{$\begin{array}{l}2.0(1.1- \\
3.6)\end{array}$} & \multirow[t]{5}{*}{0.01} \\
\hline & $894(92.0)$ & $78(8.0)$ & \multirow{4}{*}{$<.001$} & \multirow{2}{*}{$\begin{array}{l}2.2 \\
(1.3- \\
3.8)\end{array}$} & 0.06 & & \\
\hline & 204 (99.0) & $2(1.0)$ & & & 0.07 & & \\
\hline $\begin{array}{l}\text { Smear not } \\
\text { done }\end{array}$ & 354 (98.3) & $6(1.7)$ & & $\begin{array}{l}0.2 \\
(0.1- \\
1.1)\end{array}$ & & & \\
\hline EPTB & & & & $\begin{array}{l}0.4 \\
(0.2- \\
1.1)\end{array}$ & & & \\
\hline
\end{tabular}




\begin{tabular}{|c|c|c|c|c|c|c|c|}
\hline \multirow{3}{*}{$\begin{array}{l}\text { Characteristics } \\
\text { Category of TB } \\
\text { patients }\end{array}$} & \multirow{2}{*}{$\begin{array}{l}\begin{array}{l}\text { Successful } \\
\text { outcomes }\end{array} \\
1899(94.9)\end{array}$} & \multirow{2}{*}{$\begin{array}{l}\begin{array}{l}\text { Unsuccessful } \\
\text { outcomes }\end{array} \\
102(5.1)\end{array}$} & \multirow{2}{*}{$\begin{array}{l}\mathrm{x}^{2} \\
\mathrm{p}- \\
\text { value } \\
0.6\end{array}$} & $\begin{array}{l}\text { Bivariate } \\
\text { analysis }\end{array}$ & & \multicolumn{2}{|c|}{$\begin{array}{l}\text { Multivariable } \\
\text { analysis }\end{array}$} \\
\hline & & & & & & & \\
\hline & 0 & 0 & 0.44 & & & & \\
\hline $\begin{array}{l}\text { New and } \\
\text { Relapse }\end{array}$ & 0 & 0 & & & & & \\
\hline Failure & $11(100)$ & 0 & & & & & \\
\hline \multicolumn{8}{|l|}{ LTFU } \\
\hline \multicolumn{8}{|l|}{ Others $(0)$} \\
\hline HIV status & $1714(96.0)$ & $72(4.0)$ & 45.7 & 1 & $<001$ & $3.9(2.4-$ & $<001$ \\
\hline $\begin{array}{l}\text { Negative } \\
\text { Positive }\end{array}$ & $167(84.8)$ & $30(15.2)$ & <. 001 & $\begin{array}{l}4.2 \\
(2.7- \\
6.7)\end{array}$ & & & \\
\hline ART initiated?* & $145(85.3)$ & $25(14.7)$ & 0.6 & & & & \\
\hline Yes & $19(79.2)$ & $5(20.8)$ & 0.43 & & & & \\
\hline No & & & & & & & \\
\hline
\end{tabular}

* The odds ratio (OR) $(95 \% \mathrm{Cl})$ are based on 158 HIV positive study participants

$X^{2}=$ chi square; $P$ value $<0.05$ was considered statistically significant.

\section{Discussion}

This study provides evidences on trends of the key indicators of TB program performance (case notification, treatment outcomes, and factors associated with unsuccessful treatment outcomes), which are very important to improve the effectiveness of TB control and prevention programs in Dadaab and Kakuma refugee camps in Kenya.

In settings TB surveillance system is well established (with very minimal underdiagnoses and underreporting of TB cases), TB case notifications can be used as a proxy for TB incidence estimates. In the two refugee camps, there was $11.1 \%$ decline in the number of notified TB cases in three years (2014 to 2016), but increased by $16.9 \%$ in one year (2016 to 2017) (Table 1). Similarly, a decline in total TB case notification from 2014 to 2016, and an increase by 12\% from 2016 to 2017 was reported by NTLD-P of Kenya [20].

Several factors may contribute for the decline in case notification (2014-2016), including: real decrease in TB transmission; a decrease in refugee population from 378,505 in 2014 to 312,713 in 2016 [16]; continuous decline in HIV infection and increase in ART (Table 1). On the other hand, the sharp increase 
(16.9\%) in case notification in one year (2016-2017), despite the sharp decrease in refugee population from 312,713 in 2016 to 395,870 in 2017 [16), could be due to an increase in TB transmission, or improving case detection, and reporting. In summary, our findings regarding the trend in case notification need to be carefully interpreted and further research should be conducted to identify the possible contributing factors for the increase/decrease of the notified cases which will help to plan objective based interventional measures.

Bacteriologic TB diagnosis, allows patients to be correctly diagnosed and started on the most effective treatment regimen, and is critical for infection control. On the other hand, clinical diagnosis of TB which have low specificity, may lead to false diagnoses of TB, and lead patients to unnecessary treatment. The priorities of a TB programme is therefore, first to identify and treat infectious TB patients with smearpositive pulmonary TB. Thus, in order to understand the statute of bacteriologic/clinical TB diagnosis in the refugee camps, we further stratified the trends of notified TB cases by diagnostic category (Table 1 and Fig. 1).

Overall, despite the decline in total cases notification (2014-2016), there was an increase in percentage of smear positive PTB (PTB+) among the total TB cases from 2014 (41.7\%) to 2017 (47.5\%), and in percentage of bacteriologically confirmed among new and relapse pulmonary patients from 2014 (49.5\%) to 2017 (60.9\%). However, by 2017, the percentage of bacteriologically confirmed new and relapse pulmonary patients in this study (60.9\%) was lower than the WHO 2018 report for Kenya (67\%) and for Africa Region (66\%) [21]. The increase in bacteriologically confirmed cases could be due to improved access/use of diagnostic services, improvement in recording and reporting, an increase in real TB transmission, or only highly presumptive cases were tested (leading to missed cases). In addition, on average, $39.1 \%$ of the pulmonary new and relapse cases in 2017 were diagnosed clinically (Table 1), which is higher than the WHO 2018 report for Kenya (34\%) [21]. This implies, significant number of patients may lead to unnecessary TB treatment, economic burden and psychological stress.

Putting together the gaps observed in TB diagnosis in the refugee camps (low bacteriological confirmation, high clinical diagnosis) can be addressed by improving the quality-assured TB diagnostics laboratories, referral system, early case identification, access/use of advanced diagnostics, recording and reporting, and refresher training.

Evidence on TB epidemiology by type of TB (PTB and EPTB) is important to plan and implement targeted TB diagnostic, treatment and prevention services. In this study, percentage of EPTB increased by $30.2 \%$ in four years (2014-2017). Thus by 2017 , EPTB contributed to $21.1 \%$ of the total cases notified which is higher than the global (14\%) and national/Kenya (16\%) share of EPTB reported by WHO 2018 [21]. Therefore, the increased trend in the proportion of EPTB in the refugee camps which could be due to expansion of TB diagnostic services (Gene Xpert, culture and/or histopathology) or due to real change in the epidemiology of TB, need to be investigated.

We further analyzed how age and gender contributed to the total cases notified which is important for targeted intervention. Several studies evidenced gender inequity in TB cases [21-24]. In this study, 
notified TB cases were predominated by men during the study period (Table 1) in almost all age categories across the years (Fig. 3). However, the share of men by 2017 (54.7\%) was lower than the WHO 2018 report for the globe (64\%) and for Kenya (67.1\%) [21]. Similarly, the M:F ratio for notification by 2017 (1.2), was lower than WHO 2018 report for the global (1.7) and for African and Asian countries (2.7) [21]. Although there is need for further study, this could indicate women in the refugee camps may be accessing TB services at better level than in the general population in Kenya.

It is not well defined whether the high TB burden in men is due to gender-specific sociocultural factors influencing TB exposure and/or access to healthcare, or due to biological reasons that women are less susceptible to TB infection and reactivation [25-28]. However, studies showed that women are less likely than men to report or show evidence of typical symptoms of pulmonary TB [29, 30]. Hence, the lower case notification for women in the refugee camps (despite that $>70 \%$ of refugees are women and children) emphasize the need of special TB case detection and diagnosis targeting women.

TB affects all age groups. People in the age group $25-24$ years in the globe [21] and age groups 2544 years in Kenya [20] were disproportionately affected by TB. Similarly, the first and second largest contributors to the total TB cases notified across the study period in this study were age groups 1529 years (31.9\%-37.6\%) and 30-44 years (21.0\%-25.8\%) (Table 1). Therefore, since people in the age group 15-44 years is of reproductive age and represents an active component of the workforce, TB programs should strengthen interventions and case finding efforts focused on this age group.

Usually, the source of infection for children is an infectious adult mainly in the household. Therefore, paediatric TB has been considered as a sentinel marker for TB transmission [30, 31]. In this study, the third higher contributor to the total notified TB cases across the study period were children $<15$ years (20.3\%- 25.8\%). Nonetheless, the contribution of childhood TB has increased by $27.1 \%$ in four years (2014 to 2017) (Table 1). By 2017 therefore, whereas $25.8 \%$ of the TB cases in this study were children, only $10 \%$ of the estimates TB incidence in the globe [21], and 9\% of all TB cases notified in Kenya [20] by 2017 were children. Although overestimation is possible that need further investigation, the increase in childhood TB in the refugee camps could be due to increase in TB transmission, increase in number of children ( $>70 \%$ of refugees in the region are women and children), introduction of improved diagnostics like Gene Xpert, or improved community mobilization and contact tracing.

It has been a national mandate to test everyone diagnosed with TB for HIV infection. By 2017, HIV testing was performed in $97.1 \%$ of the TB patients in the refugee camps, among those $7.4 \%$ were HIV positive, which is lower than the 28\% TB/HIV co infection in Kenya in 2017 [20]. Moreover, 97.5\% of the HIV positive TB patients in the refugee camps in 2017 were on ART. This is higher as compared to the $95 \%$ ART coverage for HIV positive TB patients in Kenya in 2017 [20]. Together, results of this study evidenced the strong collaboration between TB and HIV programmes, and collaboration among NTLP and other health care givers in the refugee camps which need to be maintained.

According to WHO global target, at least $90 \%$ treatment success rate need to be achieved by 2020 among people on TB treatment in order to end TB by 2035 [21]. Treatment success rate for all TB patients 
registered in the refugee camps during the study period was higher and stable at $92.6-94.9 \%$. This is higher than the $90 \%$ global target of treatment success [20]; than the TB treatment success achieved for new and relapse TB cases in the global (82\%) and in Kenya (81\%) registered in 2016 [21], for Syrian refugees in Turkish (63.6\%) [32], and for Gambella refugees in Ethiopia (74.2\%) [31].

Over the study period, there was a decline in percentage of death and not evaluated cases but an increase in treatment failed and LTFU (Table 2). Furthermore, by 2017, the percentage of treatment failed $(0.5 \%)$, LTFU (2.3\%), died (2.2\%), and not evaluated (1.6\%) in the refugee camps were far lower than death rate (6\%), "not evaluated" (4\%), and LTFU (5\%) for the 2016 cohort of TB cases in Kenya [20]. These unfavorable treatment outcomes can be further improved by enhancing TB recording and reporting system, refresher training, supportive supervision, regular monitoring and evaluation, communication and collaboration health care providers, and by engaging patients and community mobilizers in lost to follow up tracing.

Identify, treat and cure infectious TB patients with smear-positive pulmonary TB is the most effective means of reducing TB transmission in the family and community. In the refugee camps, the percentage of cured patients increased by $49.4 \%$ in four years (2014 to 2016$)(52.0 \%)$, and then decreased by $23.7 \%$ in one year (2016 to 2017). This was far lower than the percentage of cured patients (69\%) for the 2016 cohort in Kenya [20]. Percentage of cured patients can be increased by improving follow-up sputum smear and culture examination, recording and reporting system, refresher training, and engagement of patients, care giver and communities.

Understanding factors associated with unsuccessful TB treatment outcomes can help to design evidence based intervention and to reduce morbidity and mortality. In this study, the risk of unsuccessful treatment outcomes were age $>15$ years (which increased with age), pretreatment weight $<40 \mathrm{Kg}$, being male, being smear positive PTB (PTB+) and HIV infection as discussed below.

The association of older age with successful treatment outcomes in this study is in support to other reports $(33,34]$. The possible reasons for the unsuccessful treatment outcomes among older TB patients are higher lost to treatment follow ups rates and deaths [35] and atypical clinical presentations in the elderly which can affect early TB diagnosis leading to increased mortality [36].

We showed also being female was less likely to have unsuccessful treatment outcome compared to male patients $(O R=0.49)$ (Table 3$)$ and trend of treatment success was higher for women than for men across the years (Fig. 4B). Other studies also showed gender variation in treatment outcomes [37-39]. It is possible, therefore, there may be gender specific sociocultural factors which influence response to treatment outcome $[38,39]$. Although poorly understood and need to be investigated, other biological reasons (gender-specific pharmacodynamics in particular) could contribute for the observed differences in the treatment outcome [39]. In addition, the fact that women are more likely than men to adhere to full course of treatment could result in better treatment outcomes [39]. 
Our results that HIV infected patients are more likely to have high probability of unsuccessful treatment outcomes compared with HIV negative TB cases is in line with other reports [40]. This could be due to less adherence of HIV patients to TB treatment due to drug burden or it could be due to less drug absorption related to drug-drug interaction. In summary, our multivariate analysis showed the need for special socioeconomic support and monitoring for patients who are at risk for unsuccessful treatment outcomes who are older age, pretreatment weight $<40 \mathrm{Kg}$, PTB + and HIV infected.

\section{There are limitations in this study need to be considered}

Since this study was conducted retrospectively based on secondary data from the TB register in the refugee health facilities, data incompleteness could be an issue. However, maximum effort was done to maintain the data quality standards during data extraction including intensive training to data collectors and supervisors, supervision and data re-entry at the field, and verification during data analysis. In addition, the use of secondary data did not permit us to analyse socioeconomic factors, health system factors and patient related factors that may be associated with unsuccessful treatment outcomes

\section{Strength of the study}

Despite these limitations, we have provided useful information of four year timespan on the performance of TB program (TB case notification, profile, treatment outcomes, factors associated with unsuccessful treatment outcomes) that will help to guide and improve future TB control and prevention efforts in Dadaab and Kakuma refugee camps.

\section{Conclusions}

This study has provided evidences which will help to improve TB programs in the refugee camps. There was a decline in the number of notified TB cases from 2014-2016 (11.1\% decrease) but increased in 2017 (16.9\% increase in one year). Case notification was predominated by men and age 15-29 years during the study period. There was increased trend in percentages of EPTB, and in contribution of children ( $<15$ years) to total TB cases and to EPTB. Proportion of bacteriologically confirmed new and relapse pulmonary patients increased overtime. TB treatment success during the study period $(92.6 \%$ $94.4 \%)$ was higher than the global target $(90 \%)$ and need to be maintained. There was a decreased trend in death and not evaluated treatment outcomes but an increase in LTFU. Special follow up and support is recommended for TB patients who are at risk of unsuccessful treatment (older age, pretreatment weight < $40 \mathrm{Kg}, \mathrm{HIV}$ infected). Future study is recommended to investigate the reasons for decreased trend in case notification (but increased in 2017), and increased trend in childhood TB and EPTB.

\section{Abbreviations}

aOR: adjusted odds ratio; ART: Antiretroviral treatment; DP: displaced populations; EPTB: Extrapulmonary PTB; ESRC: Scientific Review Committee; HIV: Human Immunodeficiency virus; LTFU: lost-to-follow up; MDR: multi-drug resistant; MOH: Ministry of Health; MTB: Mycobacterium tuberculosis; PTB: pulmonary 
TB; PTB+: smear positive pulmonary TB; P/Neg: smear negative pulmonary TB; TB: Tuberculosis; WHO: world health organization

\section{Declarations}

\section{Ethics approval and consent to participate}

Ethical approval was obtained from Refugee Affairs Secretariat as well as from AMREF Health Africa Ethics and Scientific Review Committee (ESRC), Kenya. This study was based on secondary data from the TB register in the refugee camps. Since patient registration number were used to maintain the study participant's confidentiality, written informed consents from the participants were not required due to the anonymous nature of the data.

\section{Consent for publication}

Not applicable

\section{Availability of data and materials}

All data generated or analysed during this study are included in this Manuscript

\section{Competing interests}

The authors declare that they have no competing interests.

\section{Funding}

This study was supported by The Global Fund to Fight Aids, Tuberculosis and Malaria, The Global Health Campus Chemin du Pommier 40, 1218, Le Grand-Saconnex, Switzerland

\section{Authors' contributions}

$T L, D A, M N$, and DK designed the research and analyzed the data. TL, SM, DA, MN, SC, FC, JO, AD, AF, FA, and DK develop the manuscript. All authors read and approved the final manuscript.

\section{Acknowledgements}

Not applicable

\section{References}

1. Van Soolingen D. Molecular epidemiology of tuberculosis and other mycobacterium infections: main methodologies and achievements. J Intern Med. 2001;249(1):1-26.

2. Global tuberculosis report 2019. Licence: CC BY-NC-SA 3.0 IGO. Geneva: World Health Organization; 2019. 
3. World Health Organization (WHO). The End TB Strategy. Geneva: World Health Organization; 2015. Available at https://www.who.int/tb/strategy/end-tb/en/.

4. Njuki C, Abera W. Forced displacement and mixed migration challenges in the IGAD region. GREAT insights Magazine- volume 7, Issue 1. Winter 2018.

5. Kimbrough W, Saliba V, Dahab M, Haskew C, Checchi F. The burden of tuberculosis in crisis-affected populations: a systematic review. Lancet Infect Dis. 2012;12:950-65.

6. WHO. 2016. Interregional workshop for tuberculosis control and care among refugees and migrant populations, 10-11 May 2016, Catania, Italy.

7. Acosta CD. Conflict and drug-resistant tuberculosis in Ukraine. Lancet. 2014;384:1500-1.

8. Ejeta E, Beyene G, Balay G, Bonsa Z, Abebe G. Factors associated with unsuccessful treatment outcome in tuberculosis patients among refugees and their surrounding communities in Gambella Regional State, Ethiopia. PLoS ONE. 2018;13(10):e0205468.

9. United Nations High Commissioner for Refugees (UNHCR). Global Trends: Forced Displacement in 2018. Geneva: UNHCR; 2019. Available at https://www. unhcr.org/5d08d7ee7.pdf.

10. WHO. (1997). Tuberculosis control in refugee situations: An Inter-agency field manual. (WHO/TB/97.221).

11. Proença R, Souza FM, Bastos ML, Caetano R, Braga JU, Faerstein E, et al. Active and latent tuberculosis in refugees and asylum seekers: a systematic review and meta-analysis. BMC Public Health. 2020;20:838.

12. Kruijshaar ME, Abubakar I. Increase in extrapulmonary tuberculosis in England and Wales 19992006. Thorax. 2009;64:1090-5.

13. WHO. International Organization for Migration, Ministry of Health of Lebanon. Joint review of the national tuberculosis programme of Lebanon. 2015.

14. United Nations High Commissioner for Refugees (UNHCR). Public Health Strategy for Tuberculosis among Syrian Refugees in Jordan, July 2013.

15. WHO. Stop TB strategy. Geneva: World Health Organization; 2006. WHO/HTM/TB/2006.368.

16. UNHCR. Refugees and asylum seekers in Kenya by country of origin and location. Available from https://www.unhcr.org/ke/wp-content/uploads/sites/2/2018/05/KENYA-Statistics-Package-April2018-Resent.pdf.

17. WHO. Definitions and reporting framework for tuberculosis-2013 revision. Geneva: WHO; 2013. WHO/HTM/TB/2013.2.

18. WHO, Compendium of WHO guidelines and associated standards: ensuring optimum delivery of the cascade of care for patients with tuberculosis, second edition. Geneva: World Health Organization; 2018. Licence: CC BY-NC-SA 3.0 IGO.

19. Ministry of Health, republic of Kenya. Guideline for integrated Tuberculosis, leprosy and lung disease in Kenya, September 2017 edition. 
20. Ministry of Health, Republic of Kenya. National Tuberculosis, Leprosy and Lung disease program (MOH/ NTLD-P. 2017). Annual report, 2017.

21. Global tuberculosis report 2018. Geneva: World Health Organization; 2018. Licence: CC BY-NC-SA 3.0 IGO.

22. Dangisso MH, Datiko DG, Lindtjørn B. Trends of Tuberculosis Case Notification and Treatment Outcomes in the Sidama Zone, Southern Ethiopia: Ten-Year Retrospective TrendAnalysis in UrbanRural Settings. PLoS ONE. 2015;10(4):e0125135.

23. Gebreegziabher SB, Yimer SA, Bjune GA. Tuberculosis Case Notification and Treatment Outcomes in West Gojjam Zone, Northwest Ethiopia: A Five-Year Retrospective Study. Journal of Tuberculosis Research. 2016;4:23-33.

24. Dogar OF, Shah SK, Chughtai AA, Qadeer E. Gender disparity in tuberculosis cases in eastern and western provinces of Pakistan. BMC Infect Dis. 2012;12:244.

25. Borgdorff MW, Nagelkerke NJ, Dye C, Nunn P. Gender and tuberculosis: a comparison of prevalence surveys with notification data to explore sex differences in case detection. Int J Tuberc Lung Dis. 2000;4:123-32.

26. Gosoniu GD, Ganapathy S, Kemp J, Auer C, Somma D, Karim F, et al. Gender and socio-cultural determinants of delay to diagnosis of TB in Bangladesh, India and Malawi. Int J Tuberc Lung Dis. 2008;12(7):848-55.

27. Tadesse S, Tadesse T. Treatment Success Rate of Tuberculosis Patients in Dabat, Northwest Ethiopia. Health. 2014;6:306-10.

28. Balasubramanian R, Garg R, Santha T, Gopi PG, Subramani R, Chandrasekaran V, Thomas A, et al., 2004. Gender disparities in tuberculosis: report from a rural DOTS programme in south India. Int J Tuberc Lung Dis.2004; 8: 323-332.

29. Morishita F, Furphy VB, Kobayashi M, Nishikiori N, Eang MT, Yadav R-P. Tuberculosis case-finding in Cambodia: analysis of case notification data, 2000 to 2013. West Pac Surveill Response. 2015;6(1):15-24.

30. Thorson A, Diwan VK. Gender inequalities in tuberculosis: aspects of infection, notification rates, and compliance. Curr Opin Pulm Med. 2001;7:165-9.

31. Shingadia D, Novelli V. Diagnosis and treatment of tuberculosis in children. Lancet Infect Dis. 2003 Oct;3(10):624-32.

32. Dogru S, Doner P. Frequency and outcomes of new patients with pulmonary tuberculosis in Hatay province after Syrian civil war. Indian J Tuberc. 2017;64:83-8.

33. Hamusse SD, Demissie M, Teshome D, Lindtjørn B. Fifteen-year trend in treatment outcomes among patients with pulmonary smear-positive tuberculosis and its determinants in Arsi zone, Central Ethiopia. Glob Health Action. 2014;7:25382.

34. Lefebvre N, Falzon D. Risk factors for death among tuberculosis cases: analysis of European surveillance data. Eur Respir J. 2008;31(6):1256-60. 
35. Rajagopalan S. Tuberculosis and aging: a global health problem. Clin Infect Dis. 2001;33(7):1034-9.

36. Jamtsho $\mathrm{T}$, et al. The burden and treatment outcomes of extra-pulmonary tuberculosis in Bhutan. Public Health Act. 2013;3(1):38-42.

37. Feng JY, Huang SF, Ting WY, Chen YC, Lin YY, Huang RM, et al. Gender differences in treatment outcomes of tuberculosis patients in Taiwan: a prospective observational study. Clin Microbiol Infect. 2012;18(9):E331-7.

38. Allotey P, Gyapong M. Gender in tuberculosis research. Int J Tuberc Lung Dis. 2008;12(7):831-6.

39. Murphy ME, Wills GH, Murthy S, Louw C, Bateson ALC, Hunt RD, et al. Gender differences in tuberculosis treatment outcomes: a post hoc analysis of the REMoxTB study. BMC Med. 2018;16:189.

40. Sisay S, Mengistu B, Erku W, Woldeyohannes D. Directly Observed Treatment Short-course (DOTS) for tuberculosis control program in Gambella Regional State, Ethiopia: ten years' experience. BMC Research Notes. 2014;7:44.

Figures

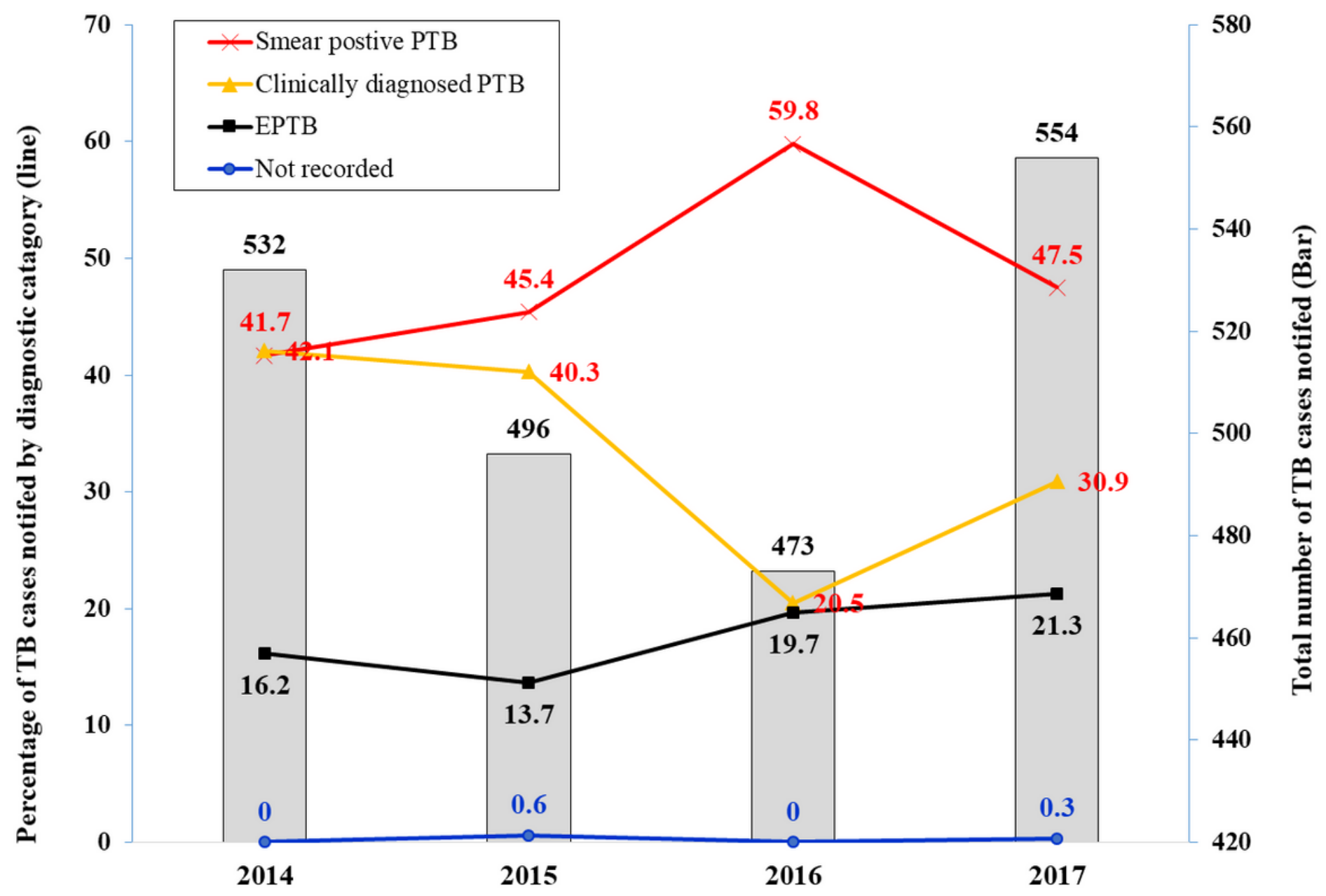

Figure 1 
Trends in number of TB cases notified (bar) by diagnostic category (line) in Dadaab and Kakuma refugee camps, Kenya, 2014-2017.

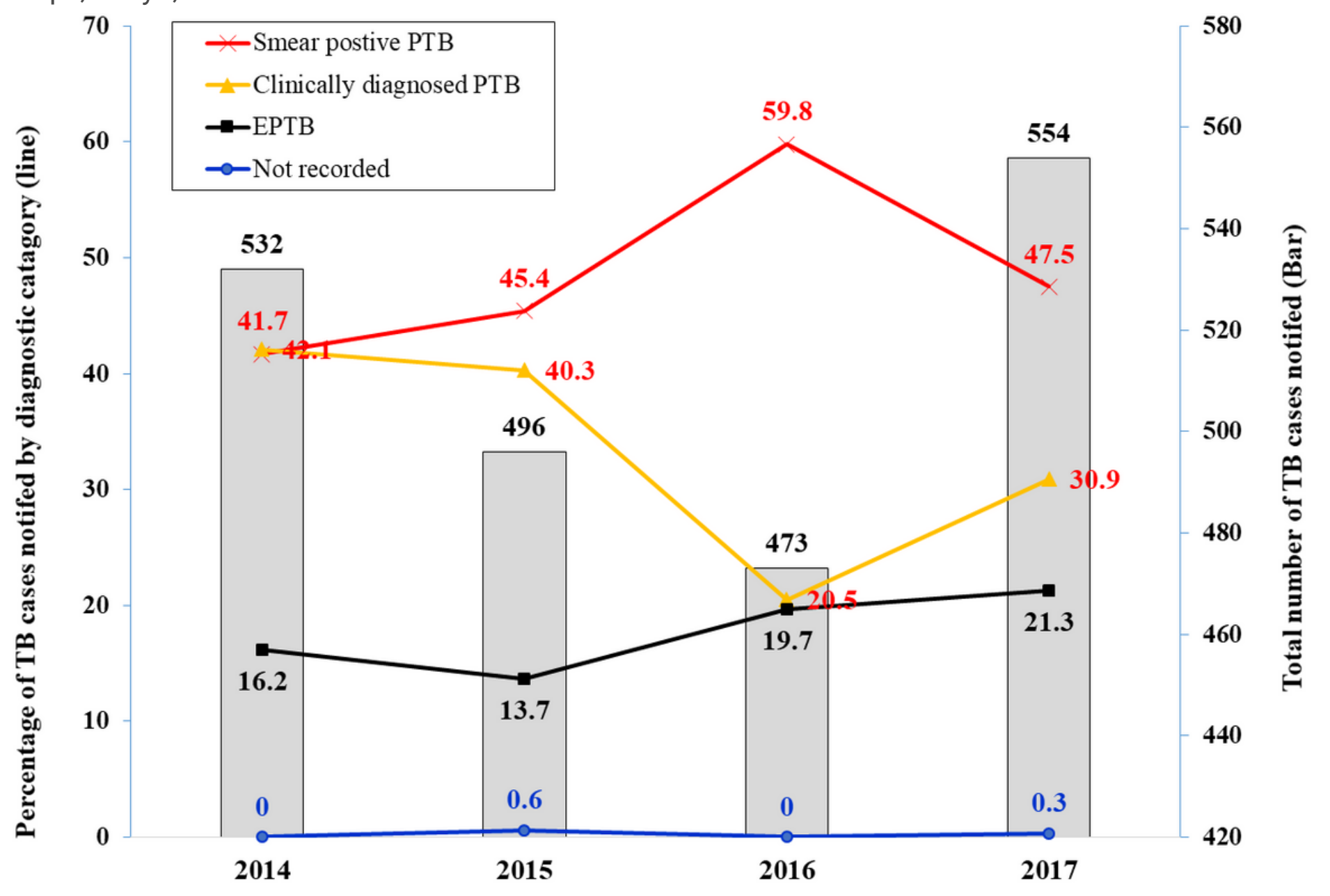

\section{Figure 1}

Trends in number of TB cases notified (bar) by diagnostic category (line) in Dadaab and Kakuma refugee camps, Kenya, 2014-2017. 


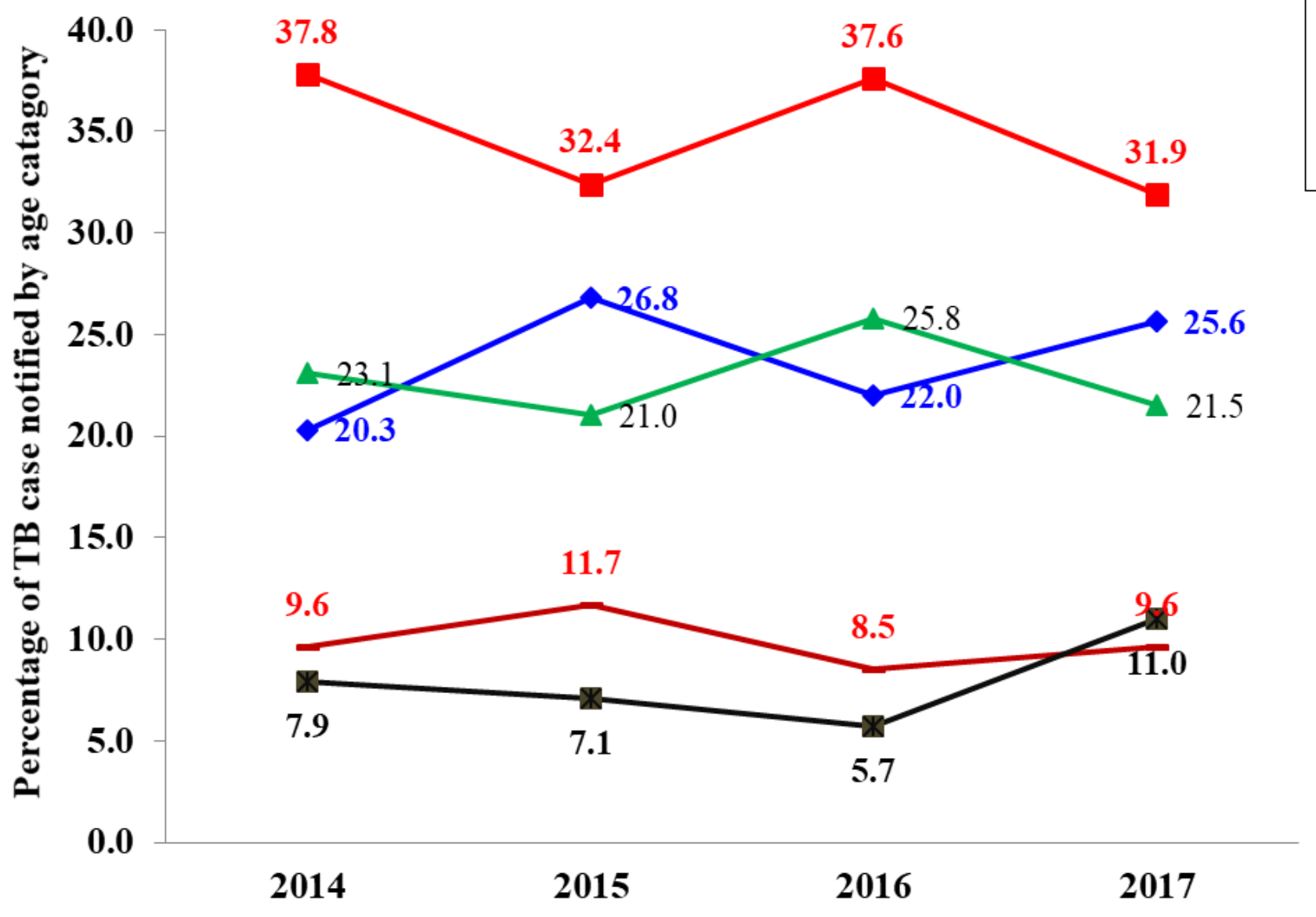

Figure 2

Trends in notified TB case of all forms stratified by age categories in Dadaab and Kakuma refugee camps, Kenya, 2014-2017 


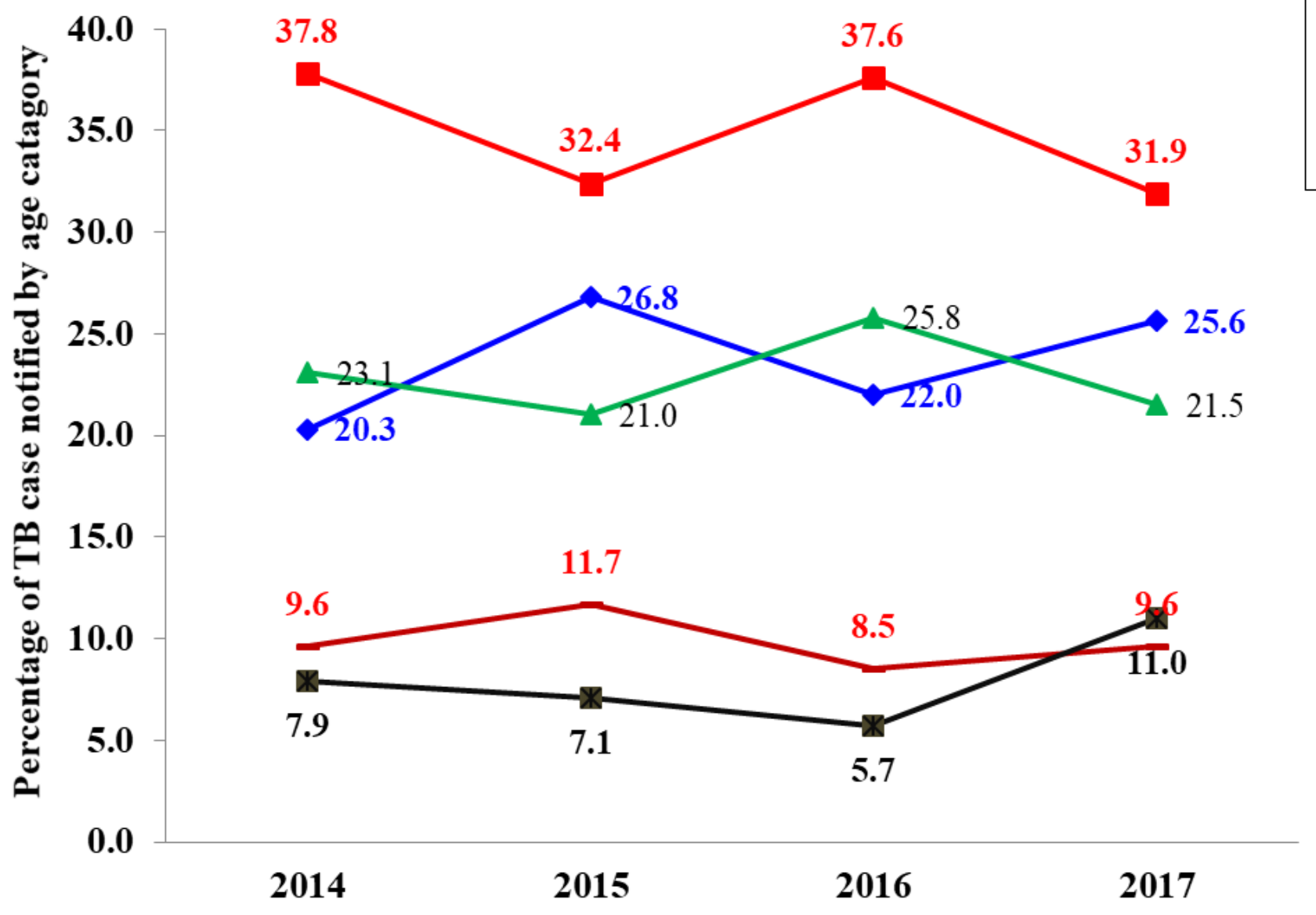

Figure 2

Trends in notified TB case of all forms stratified by age categories in Dadaab and Kakuma refugee camps, Kenya, 2014-2017 


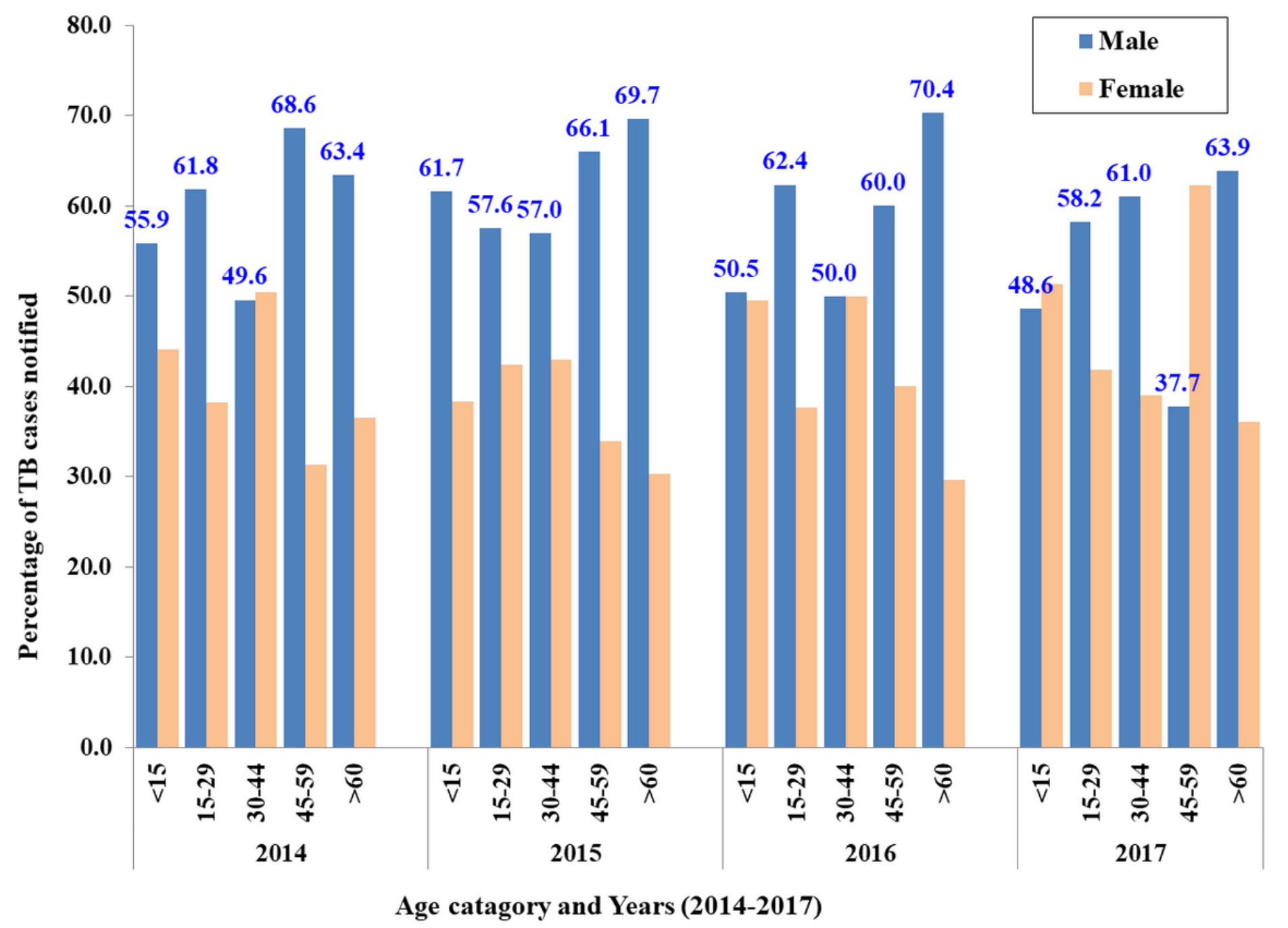

Figure 3

Trends in TB cases notified segregated by age and gender in Dadaab and Kakuma refugee camps, Kenya, 2014-2017 


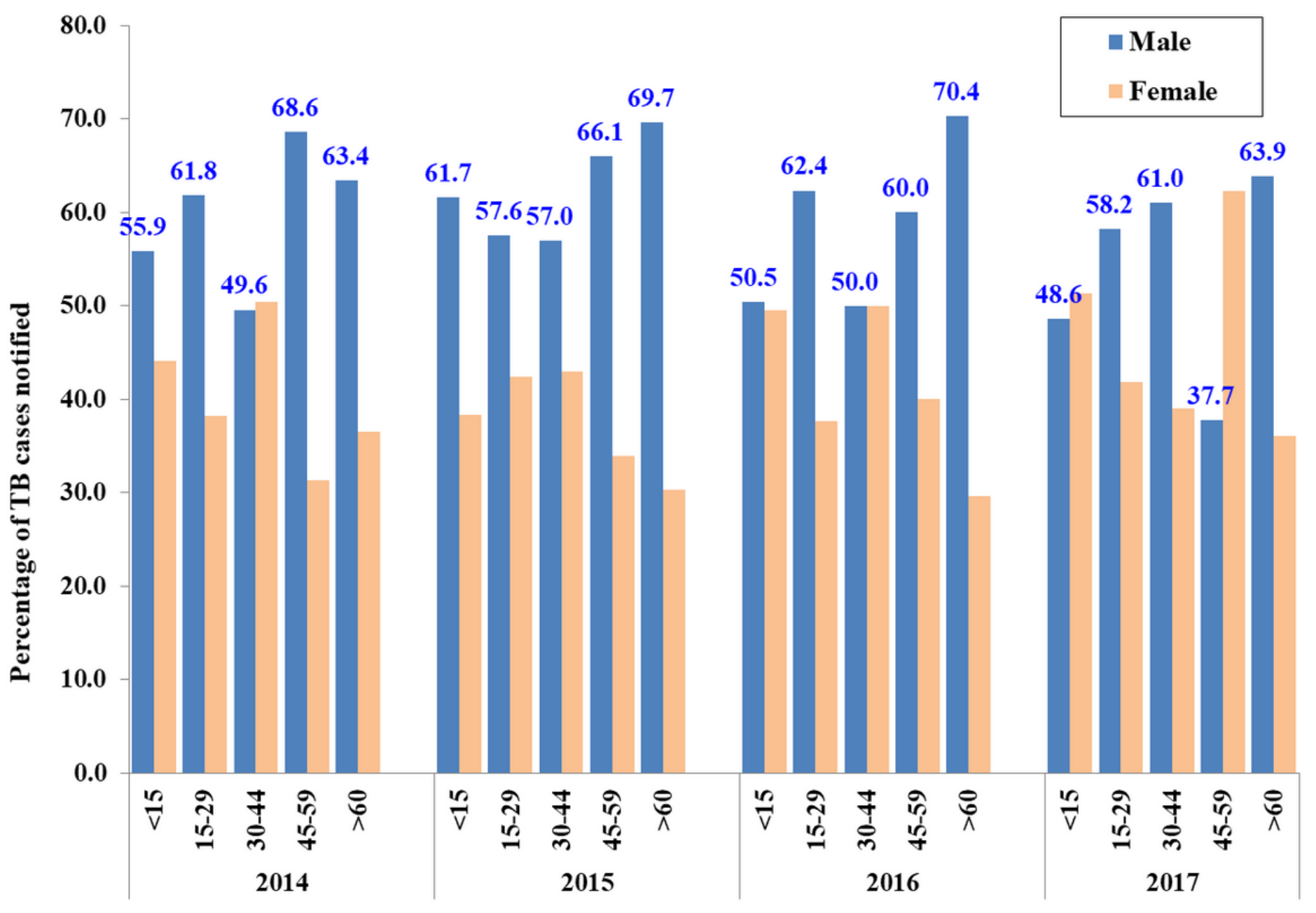

Age catagory and Years (2014-2017)

\section{Figure 3}

Trends in TB cases notified segregated by age and gender in Dadaab and Kakuma refugee camps, Kenya, 2014-2017
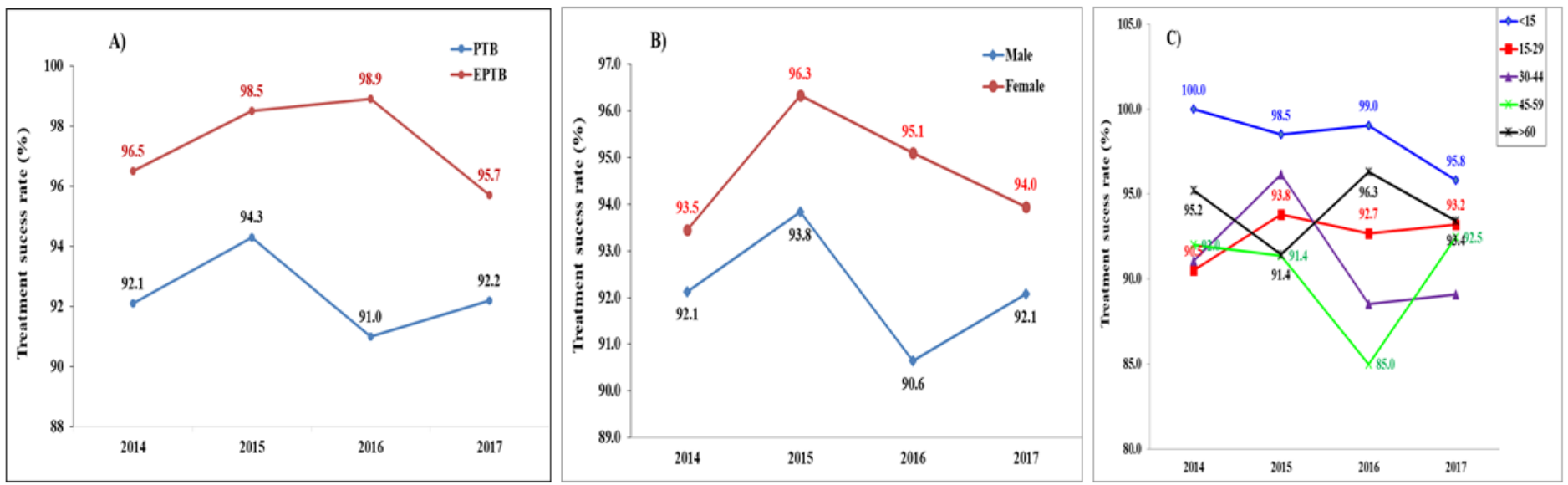

Figure 4 
Trends in TB treatment outcomes of the TB cases registered in Dadaab and Kakuma refugee camps, Kenya, 2014-2017: by Type of TB (A), by gender (B), and by age category (C)
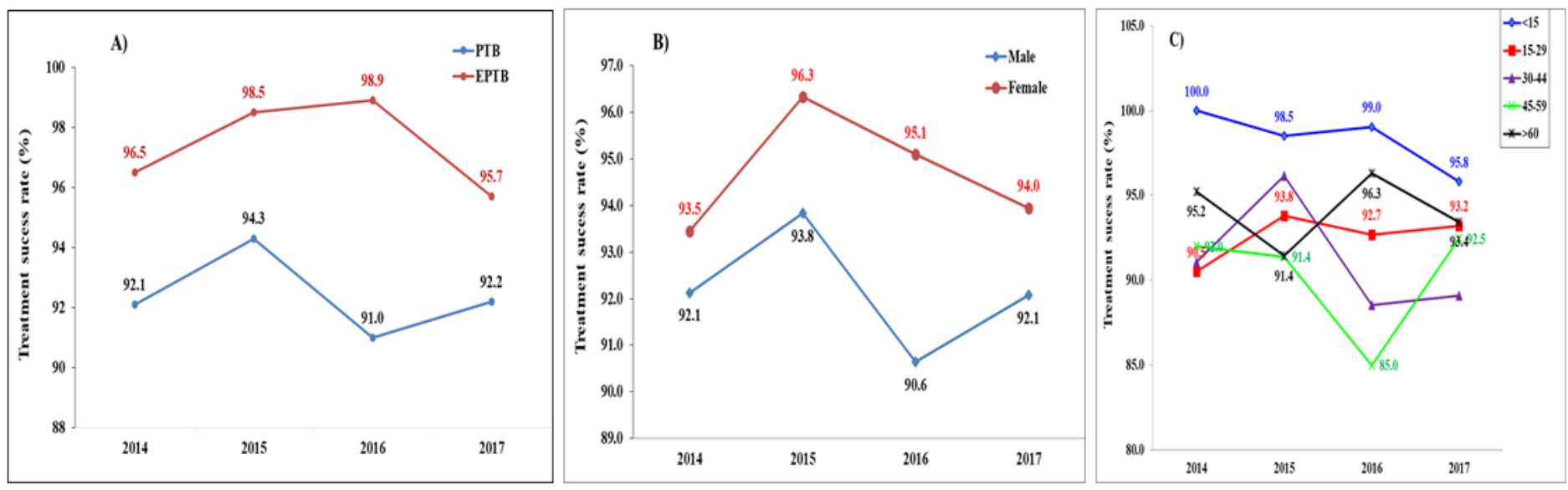

\section{Figure 4}

Trends in TB treatment outcomes of the TB cases registered in Dadaab and Kakuma refugee camps, Kenya, 2014-2017: by Type of TB (A), by gender (B), and by age category (C)

\section{Supplementary Files}

This is a list of supplementary files associated with this preprint. Click to download.

- Supplement.docx

- Supplement.docx 